\title{
LETTERS
}

\section{Natural health products are subjected to rigorous process prior to market}

I agree with some of what Dr. Stanbrook states in his editorial, ${ }^{1}$ particularly with regard to lack of enforcement by Health Canada's Natural and Non-prescription Health Products Directorate in removing natural health products from store shelves if they are dangerous or profess unsubstantiated claims. I also concur that some of the proposed changes to the original 2004 Natural Health Products Directorate regulations require further thought, and the organization that I represent submitted an extensive list of criticisms and possible amendments. For example, classifying natural health products as low, medium or high risk begs the question of the means by which these products are classified as such.

However, I must protest the insinuation by Dr. Stanbrook that natural health products do not undergo as rigorous a process as pharmaceutical drugs with regard to proof of concept, claims, etc. I have 13 years of post-secondary education in the field of nutritional sciences, with expertise in the area of natural health products, as well as more than 15 years of experience with natural health product clinical trials. I can assure Dr. Stanbrook that the clinical trials we design, implement and complete undergo the same level of rigorous regulatory oversight as drug trials. We must submit extensive clinical trial applications to both Health Canada and an independent research ethics board; we require all of the same documentation for our trials, including adverse event statistics; and many of our findings are published in peer-reviewed, prestigious journals. Natural health products are not allowed to make therapeutic claims; thus, any of these products with claims of treatment or cure are, in fact, subject to removal from store shelves, albeit via the purview of Health Canada's currently lax enforcement procedures.

Some claims - such as structure/function claims - are permitted, provided that sufficient evidence of both safety and efficacy are available, and this usually means a well-conducted, placebo-controlled, randomized clinical trial. For Dr. Stanbrook to state that these products make "similar health claims with little or no evidence and are frequently grounded in unscientific belief systems about health and disease" is to completely denigrate the entire education and work experience of myself and others working in this field. I would suggest that my knowledge of natural health products far exceeds his or that of any other doctor graduating from a Canadian medical school, in light of the short shrift given to both nutrition in general and natural health products in particular. I would invite Dr. Stanbrook to visit our facility in Guelph at any time, to see for himself the quality of work we do in the field of natural health products. If Dr. Stanbrook really wants to see shelves of products claiming to cure everything from alopecia to xerophthalmia, he should take a look south of the border, where health food stores are a virtual cornucopia of unregulated products.

\section{Maggie Laidlaw PhD}

Director of Scientific Affairs, Nutrasource

Diagnostics Inc., Guelph, Ont.

Cite as: CMAJ 2017 October 10;189:E1267. doi: $10.1503 / \mathrm{cmaj} .733293$

\section{Reference}

1. Stanbrook M. Natural health products should be sold separately from drugs. CMAJ 2017;189:E848.

Competing interests: I am employed by a contract research organization, Nutrasource Diagnostics Inc. 